\title{
Damage Analysis of Composite Sheet Under Thermal Load
}

\author{
AMER KARNOUB ${ }^{1}$, KOAST PARKIZDINS ${ }^{1}$, ANTYPAS IMAD REZAKALLA ${ }^{2 *}$, \\ DYACHENKO ALEXEY GENNADYEVECH ${ }^{2}$ \\ ${ }^{1}$ Institute of Polymers, Department of Materials, ETH Zurich, 8093, Zurich, Switzerland \\ ${ }^{2}$ Don State Technical University. Gagarin square 1, Rostov-on-Don, 344000, Russian Federation
}

\begin{abstract}
The goal of this research is to carry out a 3-dimensional finite detail approach evaluation of a composite plate cracked under thermal loading. The results of the mechanical properties of the composite, the orientation angle of the fibers, the geometric form of the plate, the thermal loading and the crack length had been studied to show their influence on the variation of the integral J. It is concluded that the integral J increases with the increase of crack size, temperature variation and reduce in fiber orientation perspective ( $\theta)$. To complete the work a probabilistic analysis was carried out.
\end{abstract}

Keywords: thermal analysis, damage, composite, probabilistic analysis

\section{Introduction}

Composite materials are used an increasing number of regularly for the manufacturing of structural parts. Despite being anisotropic and heterogeneous, their unique mechanical properties certainly make it feasible to lighten structures, mainly while they may be added into enterprise sectors such as aeronautics, automotive and sport. Thus, the three main classes of composite materials, with ceramic, metal and polymer matrices, are experiencing sustained development [1-6]. A composite fabric includes a matrix and a reinforcement, made from fibers and fillers. The matrix is itself composed of a resin (polyester, epoxy, etc.) and fillers the cause of that's to enhance the traits of the resin even as decreasing the manufacturing cost. From a mechanical point of view, the resin-fillers aggregate behaves like a homogeneous fabric, and the composite is taken into consideration to include a matrix and a reinforcement [7-11]. The reinforcement gives the composite fabric with its excessive mechanical overall performance, even as the position of the matrix is to transmit external mechanical stresses to the fibers and to defend the fibers in opposition to external aggressions. The kind of matrix-reinforcement affiliation relies upon on the limitations imposed at the designer, together with excessive mechanical traits, temperature resistance, cost, corrosion resistance, etc. [12-15]. The look of cracks and their propagation is one of the essential dangers of industrial structures. The geometrical discontinuity which constitutes the crack can, under certain conditions of loading, result in a disastrous leak wherein even the entire spoil of the shape. Researchers on the flip of the century attempted to recognize how a crack ought to result in the spoil of structures. The project isn't smooth due to the fact the cracks lead, in theory, to a mathematical singularity [16-18]. The goal of this research is to take a look at the overall performance of composite plates through a 3-dimensional evaluation through the finite detail approach turned into used to gain this goal. The assessment is made at the evolution of the quintessential $\mathrm{J}$ on the crack head of the plates [19]. We will spotlight the advantages and disadvantages of the different approaches, in addition to their interest for our study. And to finish the take a look at a probabilistic evaluation of the failure of the shape turned into carried out [20].

\section{Materials and methods}

\subsection{Geometric pattern}

The geometric version of the cracked composite plate is shown in Figure 1. The rectangular plate is characterized by its dimensions, its height $\mathrm{H}=80 \mathrm{~mm}$, its width $\mathrm{W}=80 \mathrm{~mm}$ and its thickness e $=3 \mathrm{~mm}$, containing a central crack of length (a) which varies from $5 \mathrm{~mm}$ up to $20 \mathrm{~mm}$. The structure made up of the composite plate is stressed by a thermal loading $\Delta \mathrm{T}=100^{\circ} \mathrm{C}$.

*email: imad.antypas@mail.ru 


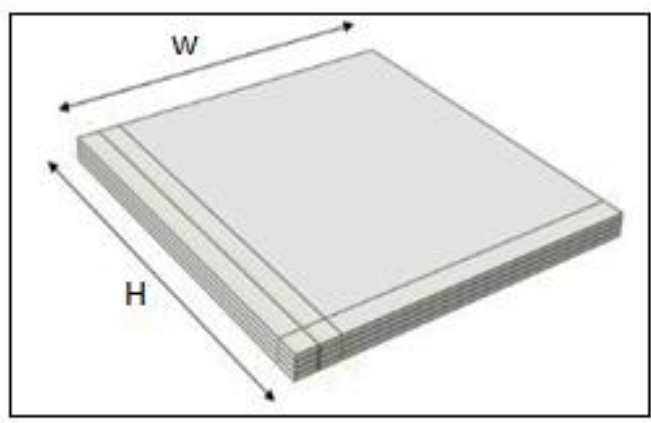

Figure 1. Descriptive model of the studied geometry

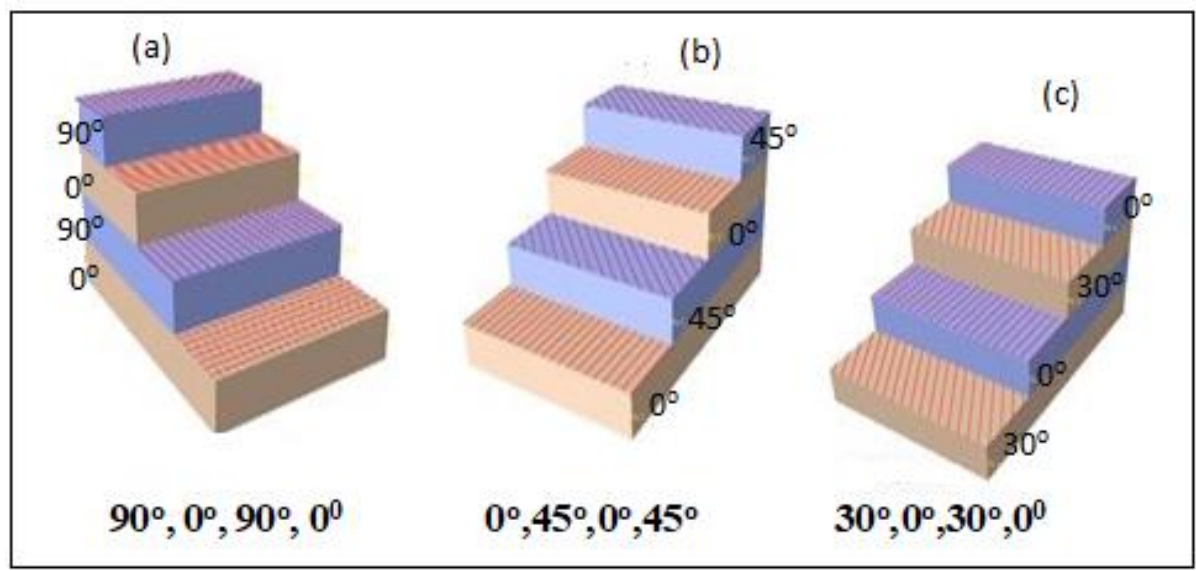

Figure 2. Descriptive model of four different angles studied

\subsection{Mechanical characteristics}

The mechanical characteristics of the plate are grouped together in Table 1.

Table 1. Mechanical properties of different materials

\begin{tabular}{|c|c|c|c|}
\hline & Boron / Epoxy & Glass / Epoxy & Graphite / Epoxy \\
\hline $\mathrm{E}_{1}(\mathrm{GPa})$ & 200 & 50 & 127.5 \\
\hline $\mathrm{E}_{2}(\mathrm{GPa})$ & 19.6 & 25 & 9.00 \\
\hline $\mathrm{E}_{3}(\mathrm{GPa})$ & 19.6 & 25 & 4.80 \\
\hline$v_{12}$ & 0.3 & 0.21 & 0.342 \\
\hline$v_{13}$ & 0.28 & 0.21 & 0.342 \\
\hline$v_{23}$ & 0.28 & 0.21 & 0.38 \\
\hline $\mathrm{G}_{12}(\mathrm{GPa})$ & 7.2 & 7.2 & 4.8 \\
\hline $\mathrm{G}_{13}(\mathrm{GPa})$ & 5.5 & 5.5 & 4.8 \\
\hline $\mathrm{G}_{23}(\mathrm{GPa})$ & 5.5 & 5.5 & 2.55 \\
\hline$\alpha_{12}\left(10^{-6} \mathrm{C}^{\circ}\right)$ & 4.5 & 5.5 & -1.2 \\
\hline$\alpha_{13}\left(10^{-6} \mathrm{C}^{\circ}\right)$ & 23 & 15 & 34 \\
\hline$\alpha_{23}\left(10^{-6} \mathrm{C}^{\circ}\right)$ & 23 & 15 & 34 \\
\hline
\end{tabular}

\subsection{Conditions to the limits}

The boundary situations of fixation, subordinate to the situations of symmetry of the geometry, have been added withinside the preliminary phase. These conditions are represented as follows in 3D: Axissymmetries compared to $\mathrm{Y}$. $(\mathrm{U} 1=\mathrm{U} 3=0 ; \mathrm{UR} 2=0)$.

\subsection{Finite element method}

One of the troubles with inside the modeling of cracked systems is the geometrical description of the crack. Within the framework of the finite detail method, it is described explicitly and paperwork a necessary a part of the borders of the mesh. Within the framework of this study, and for motives of symmetry most effective the sector of the shape is considered and is modeled via way of means of linear 
factors bricks with eight nodes. The mesh of the specimen used for the 3-dimensional numerical evaluation is shown in Figure 3. Therefore, a sophisticated mesh is made across the crack for the 3 plates whose crack sizes are equal to 5, 10 and $20 \mathrm{~mm}$. The wide variety of nodes is same to 9422 and the wide variety of factors is same to 7632 .

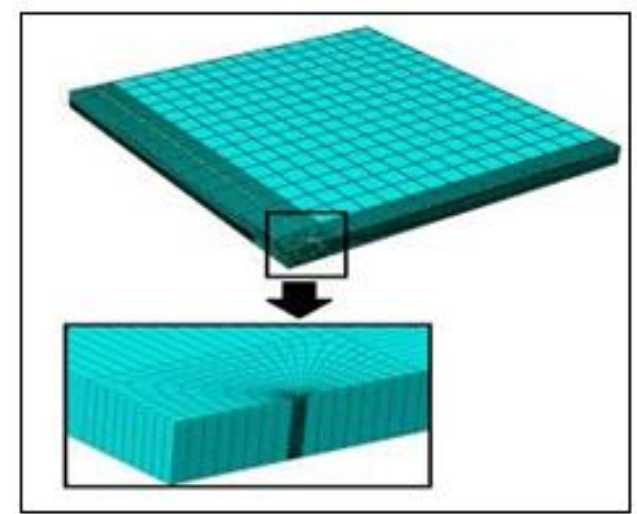

Figure 3. Mesh used of the structure in the vicinity of the crack

\section{Results and discussions}

\subsection{Effect of composite properties}

With: $E^{\prime}=E$ in plane stress; $E^{\prime}=E /\left(1-v^{2}\right)$ in plane strain

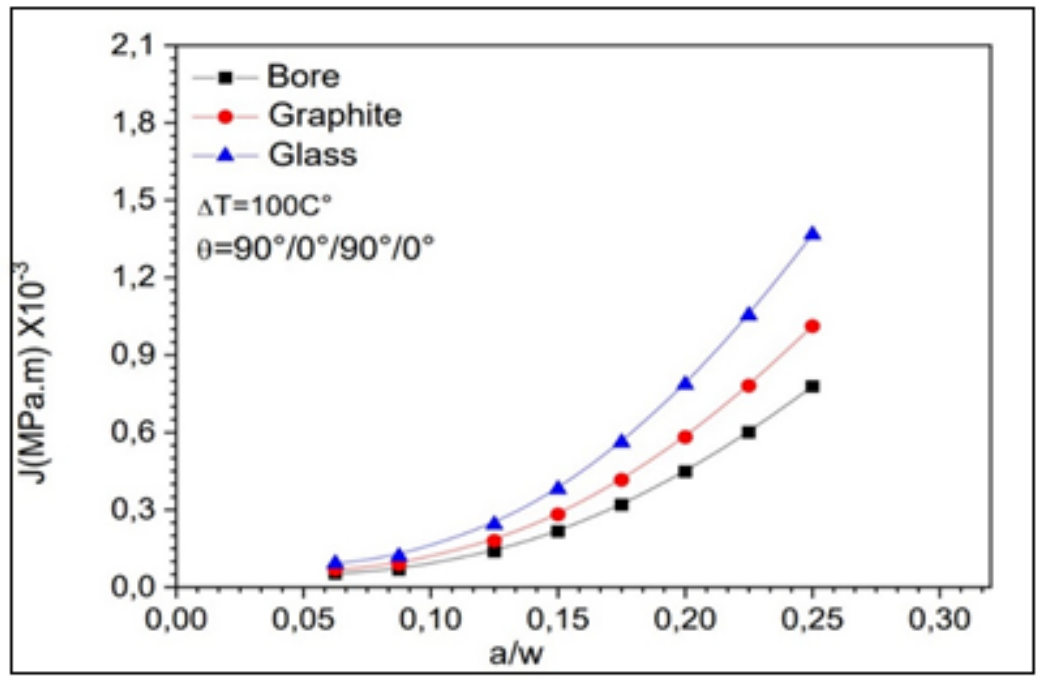

Figure 4. Variation of the integral $\mathrm{J}$ for 4 different fiber angles and 3 different composites for a rectangular plate relying at the crack size

It may be certainly visible on Figure 4 that Bore / epoxy offers precise overall performance as compared to different composites. This form of composite cloth is suggested for its use at some point of the restore of systems and for this our look at will encompass Boron / epoxy at some point of the analysis.

\subsection{Effect of fiber orientation}

Figure 5 indicates the variant of the integral $\mathrm{J}$ for 4 different angles of composite fiber for a rectangular plate as a characteristic of crack length. It is apparent that the growth with inside the crack length generates an increase in the integral J. It is stated that for the composite of fiber angle $\theta=90^{\circ} /$ $0^{\circ} / 90^{\circ} / 0^{\circ}$ generates a decrease in the value of the integral $\mathrm{J}$ of $40 \%$ with respect to the composite of 
fiber angle $\theta=45^{\circ} / 0^{\circ} / 45^{\circ} / 0^{\circ}$ and of $52 \%$ with respect to the composite of fiber angle $\theta=30^{\circ} / 0^{\circ} /$ $30^{\circ} / 0^{\circ}$.

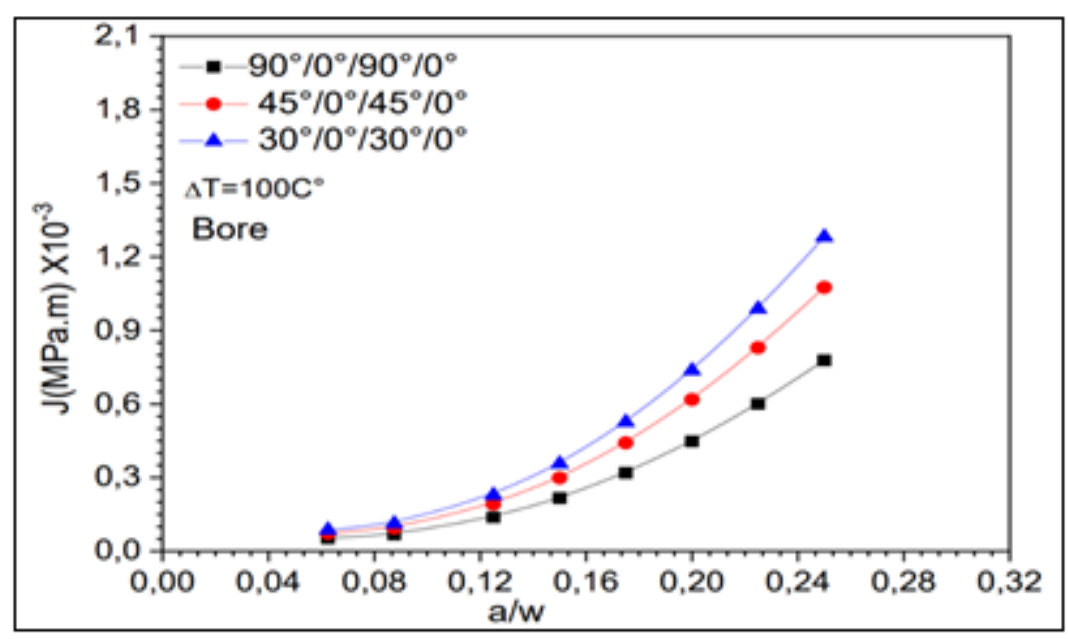

Figure 5. Variation of the critical $\mathrm{J}$ for 4 exclusive angles of composite fiber for a rectangular plate relying at the crack size

\subsection{Effect of fiber orientation}

We can clearly see in Figure 6 that the rectangular form offers proper overall performance as compared to the square shape plate due to the fact for a crack length a $=20 \mathrm{~mm}$ the distinction is $35 \%$ and reaches $70 \%$ for a trapezoidal form.

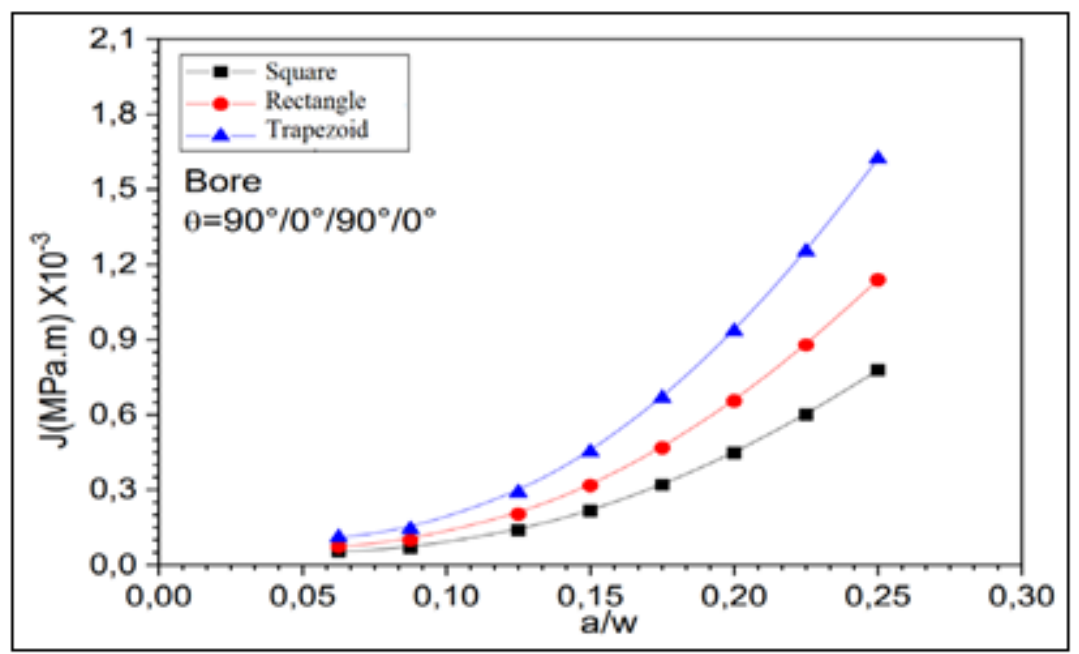

Figure 6. Variations of the integral $\mathrm{J}$ as a function of the crack length for different geometric shapes

\subsection{Temperature effect}

Figure 7 suggests the variant of the fundamental $\mathrm{J}$ in mode $\mathrm{I}$ as a characteristic of the crack duration for 3 different temperature variations $\left(\Delta \mathrm{T}=100,150,200^{\circ} \mathrm{C}\right)$, for a square shaped plate. The value of the integral $\mathrm{J}$ is proportional to the crack size and that increasing the temperature variation increases the integral J. 


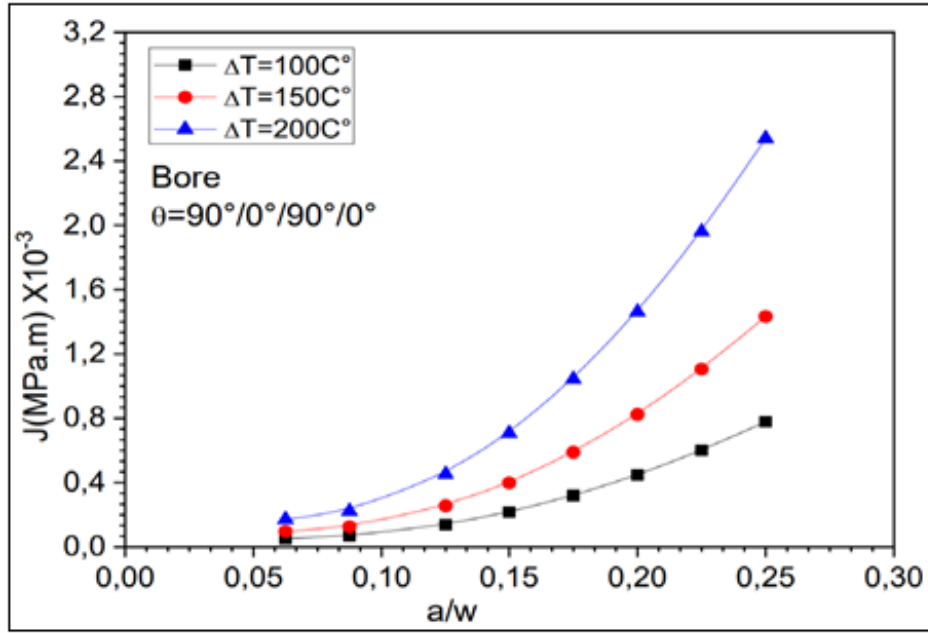

Figure 7. Variations of the integral $\mathrm{J}$ as a function of the crack length for three different values of $\Delta \mathrm{T}$

\subsection{Probabilistic analysis of mechanical failure}

The opportunity of failure is expected through modeling the uncertainties withinside the implemented load. The properties of substances and the geometry of systems are taken as random variables which might be described mainly through the opportunity distribution functions. We keep in mind a shape with mechanical and geometric traits that is subjected to random loads. We denote through $\mathrm{X}$ a random vector with $\mathrm{N}$ dimensions with additives which signify all of the uncertainties withinside the gadget and cargo parameters. For example, the viable random additives are: the geometric parameters $\mathrm{H}, \mathrm{W}, \mathrm{a}$, and the mechanical properties $\mathrm{E}, v, \alpha$. All or a number of those variables may be modeled as random variables. Therefore, any applicable reaction to the break, which includes the $\mathrm{J}(\mathrm{X})$, ought to be evaluated through the opportunity. The density feature is evaluated the use of the Monte-Carlo method. The fundamental concept is to take random samples for the enter parameters after which calculate the reaction for every pattern through the Monte Carlo method. A statistical evaluation of the reaction units is furnished to acquire excessive precision of the results, we executed one hundred and five simulations. Figure 8 represents the histograms of $(\mathrm{J})$ acquired through the Monte Carlo simulations. The opportunity density feature (pdf) is acquired through becoming the histogram with theoretical fashions from determine 7.

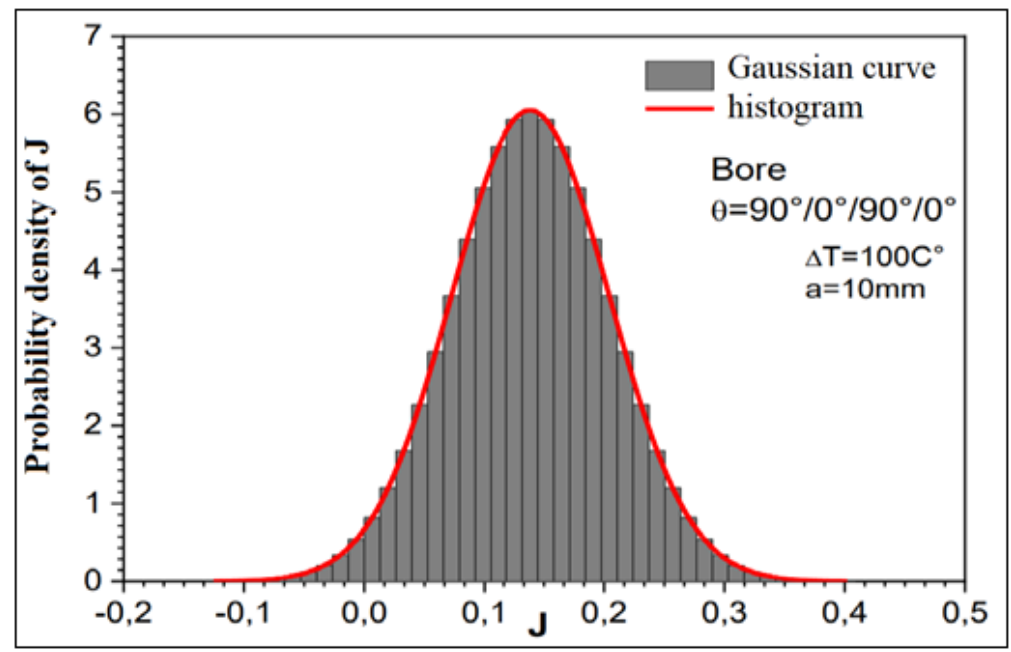

Figure 8. Histogram and Probability of the density function of $\mathbf{J}$ 
Reliability - primarily based totally layout, the uncertainties are taken into consideration with the aid of using thinking about the protection margin (J) (xi) defined in phrases of random variables (xi) which outline the uncertainties. The protection margin $(\mathrm{J})(\mathrm{xi})$ is the probabilistic layout rule, which defines the protection of the plate with the aid of using the condition (J) (xi)> zero and the failure of the plate with the aid of using (J) (xi) <zero. Figures $9 a$ and $b$ represent the probability density of $(\mathrm{J})$ for unique values of crack lengths (a). It may be visible that after the pressure is high, the value of the probability density of $(J)$ is low. We can see that the margin will increase drastically with the uncertainties associated with the duration of the crack, which ends up in a extra chance of failure, ultimately the possibilities of failure rely upon the duration of the crack (a).

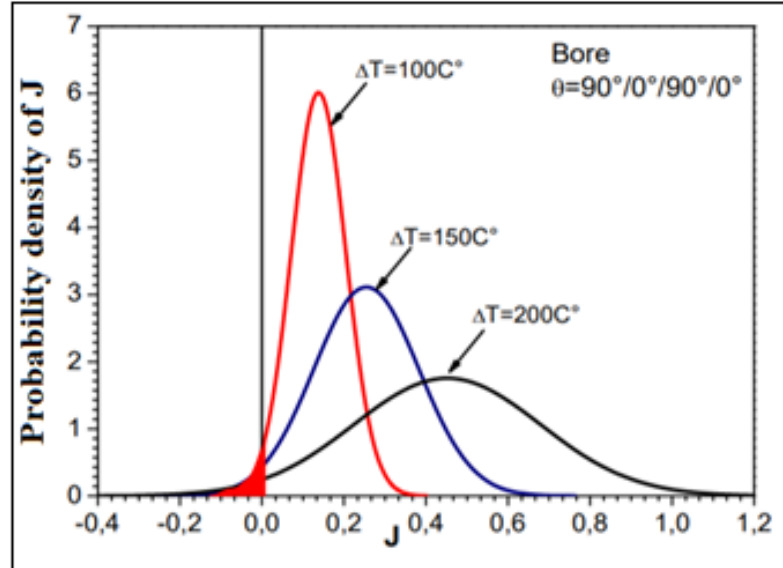

a

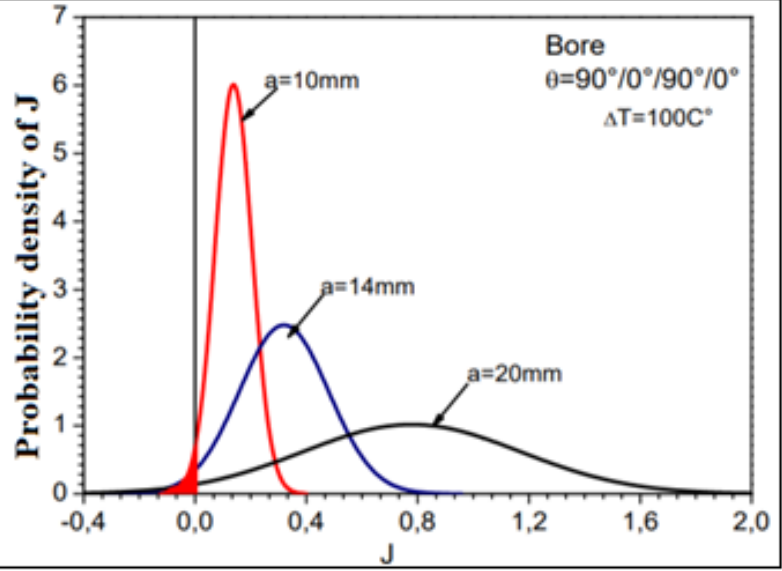

b

Figure 9. Probability density of the integral $\mathrm{J}$

a) different values of $\mathrm{T}$ for $\mathrm{b}$ ) different values of crack lengths

\section{Conclusions}

The geometrical discontinuity which constitutes the crack can, under certain conditions of loading, cause a disastrous leak in which even the entire destroy of the structure. The goal of our take a look at is to spotlight the evaluation of harm to composite plates in addition to the outcomes obtained. The outcomes of the evaluation display that:

-for the composite where the orientation of the fibers is $\theta=90^{\circ} / 0^{\circ} / 90^{\circ} / 0^{\circ}$ there is a significant decrease in the integral $\mathrm{J}$ compared to the composite of fiber angle $\theta=45^{\circ} / 0^{\circ} / 45^{\circ} / 0^{\circ}$ and that of the fiber angle $\theta=30^{\circ} / 0^{\circ} / 30^{\circ} / 0^{\circ}$ thus we can conclude that the angle of the fibers of the composites plays a determining role on the resistance and the duration life of structures;

-square form offers top overall performance as compared to trapezoidal and square form plates;

-the possibility of structural failure is carefully associated with the crack size (a) and reduces with growing load.

Acknowledgments: This research was supported by ETH Zürich Institute. We are thankful to all our colleagues who provided expertise that greatly assisted the research, although they may not agree with all of the interpretations provided in this paper.

\section{References}

1.CHAO LI, WANG Y. J., QIN KE, LI SHU LONG, The Research Status of the Wetting of Metal/Ceramic in the High Temperature Self-Lubricating Materials. International Journal of Materials Science and Applications. Vol. 5, No. 2, 2016, 108-112. DOI: 10.11648/j.ijmsa.20160502.22 
2.KARNOUB A., HAJIAN HUANG, ANTYPAS I. R., Investigation of the impact behavior for composite materials reinforced by glass fibers. Journal of Physics: Conference Series, Volume 1515, Engineering and Innovative Technologies, 2020, 1-10.

https://doi.org/10.1088/1742-6596/1515/4/042081

3. PRASADA S. V., ASTHANAB R., Aluminium metal-matrix composites for automotive applications: tribological considerations. Tribology Letters. Vol. 17 (3), 2004, 445-453.

http://dx.doi.org/10.1023/B:TRIL.0000044492.91991.f3

4. SURAPA M. K., Aluminum matrix composites. Challenges and opportunities. Sadhana. Vol. 28, Parts $1 \&$ 2, 2003, 319-334.

5. MORTENSEN A., Metal matrix composites: Matrices and processing. In Encyclopedia of materials Science and technology TW Clyne. Elsevier, 2001.

6. MIRACLE D. B., Metal matrix composites from science to technological significance. Composite Sciences Technology. Vol. 65, 2005, 2526-40.

7. EUSTATHOPOULOS N., Wetting by Liquid Metals. Application in Materials Processing Metals. Vol. 5, 2015, 350-370. https://doi.org/10.3390/met5010350

8. KARNOUB A., PARKIZDINS K., ANTYPAS I. R., Thermal characterization of composite material plates ceramic/metal FGM. Journal of Physics: Conference Seriesthis link is disabled. 1889(4), 2021, 112. https://doi.org/10.1088/1742-6596/1889/4/042035

9. LAI Q. Q., ZHANG L., EUSTATHOPOULOS N., Enhanced wetting of dual-phase metallic solids by liquid metals: A new effect of interfacial reaction. Acta Materialia. Vol. 61, 2013, 4127-4134.

DOI: 10.1016/j.actamat.2013.03.039

10. KARNOUB, A., HUANG, H., ANTYPAS, I. R., Investigation of composite materials supported by carbon fiber fabric (TFC) in pre-cracked concrete beams. Journal of Physics: Conference Seriesthis link is disabled, 1679(4), 2020,1-15. https://doi.org/10.1088/1742-6596/1679/4/042040

11. AIZENSHTEIN M., FROUMIN N., FRAGE N., Experimental Study and Thermodynamic Analysis of High Temperature Interactions between Boron Carbide and Liquid Metals. Engineering. Vol. 6, 2014, 849-868. DOI: 10.4236/eng.2014.613079

12. ANTYPAS I.R., The influence of polyethylene processing on the plastic containers blowing. Journal of Physics: Conference Series 1515(4), 2020, 1-7.

https://doi.org/10.1088/1742-6596/1515/4/042042

13. SOHRABI BABA HEIDARY D., AKHLAGHI F., Theoretical and experimental study on settling of SiC particles in composite slurries of aluminum A356/SiC. Acta Materialia. Vol. 59, 2011, 45564568. DOI: 10.1016/j.actamat.2011.03.077

14.KANNAN S., KISHAWY H. A., Tribological aspects of machining aluminium metal matrix composites. Journal of Materials Processing Technology. Vol. 198, 2008, 399-406.

DOI: 10.1016/j.jmatprotec.2007.07.021

15. WALY M. A., IBRAHIM K. M., ABELAZIM A. N., Structure and wear properties of SiC reinforced Al-Li alloy in the cast and heat treated conditions. Canadian metallurgical quarterly. Vol. 45, 2006, 45. https://doi.org/10.1179/cmq.2006.45.4.459

16.MOHANAKUMARA K. C., RAJASHEKAR H., GHANARAJA S., AJITPRASAD S. L., Development and mechanical properties of $\mathrm{SiC}$ reinforced cast and extruded Al based metal matrix composite. Procedia Materials Science. Vol. 5, 2014, 934- 943.

https://doi.org/10.1016/j.mspro.2014.07.381

17. MEENA K. L., MANNA A., BANWAIT S. S., JASWANTI, An Analysis of Mechanical Properties of the Developed Al/SiCMMC's, American Journal of Mechanical Engineers. Vol. 1, 2013, 14-19.

DOI: 10.12691/ajme-1-1-3

18.HIMANSHU KALA, MER K. K. S., SANDEEP KUMARC, A Review on Mechanical and Tribological Behaviors of Stir Cast Aluminum Matrix Composites. Procedia Materials Science. Vol. 6, 2014, 1951-1960. DOI: 10.1016/j.mspro.2014.07.229 
19.MAZAHERY A., OSTAD SHABANI M., Characterization of cast A356 alloy reinforced with nano SiC composites. Transactions of Nonferrous Metals Society. China. Vol. 22, 2012, 275-280.

DOI: 10.1016/S1003-6326(11)61171-0

20.NEELIMA D., SELVARAJ C. N., MAHESH, V., Micro structural aspects of Aluminum Silicon Carbide Metal Matrix Composite, International Journal of Applied Science and Engineering Research, Vol. 2, 2012, 250-254. DOI:10.6088/ijaser.0020101025

Manuscript received: 0.09 .2021 